The final publication is available at Springer via https://doi.org/10.1007/978-3-319-76992-9_6.

\title{
Accessing and Using Digital Libraries in Art History
}

\author{
Christina Kamposiori, UCL Centre for Digital Humanities \\ Claire Warwick, Department of English Studies, University of Durham \\ Simon Mahony, UCL Centre for Digital Humanities
}

\begin{abstract}
Over the past decades, the increase in the use of digital resources and the growth of research conducted in digital environments has transformed academic scholarship. The goal of this paper is to highlight the importance of understanding user behavior and needs for building digital libraries and resources that have a positive effect on the whole scholarly workflow. For this purpose, the art historical discipline will be used as a case study; by employing an ethnographic approach to the study of scholarly habits, we managed to uncover the requirements that scholars in the field have in terms of accessing and using digital libraries. The complex information behavior of art historians as well as the challenges they often face when interacting with digital resources make them a great example to demonstrate the impact that digital libraries and archives can have on the research process.
\end{abstract}

Keywords: digital libraries, digital resources, information behavior, art history, access, user requirements, research, teaching 


\section{Introduction}

Technological progress and mass digitization of information resources have brought large changes to traditional scholarship in the Arts and Humanities during the past fifty years. Never before was there such breadth of information and services available for scholars to use; most importantly, though, such developments offer the advantage of not only speeding up the research process, but also for enabling innovative research inquiry. Therefore, as the employment of digital resources and methods in the Arts \& Humanities increases, so does the necessity to understand scholarly behavior and provide digital infrastructure tailored to the needs of these researchers.

The emergence of digital libraries and archives has greatly facilitated the need of Arts \& Humanities scholars for finding diverse types of information (especially secondary literature); thus, accessing and using a variety of digital resources have become a standard step in their daily work routine. Regarding art history, it is no surprise that most of the previous studies examining the practices of scholars in the field [e.g. see 6, 23, 33] have focused on the ways they look for information. This can be easily justified if we consider the importance that the initial stages of research have for the whole research process; for example, the seeking and discovery of accurate information plays a key role in producing reliable and credible results.

However, there is little research on the criteria upon which art historians' decisions are made when choosing specific digital resources as well as the impact these have in the whole research process. Against this background, we aim to explore how art historians access and use digital resources for the purposes of research and teaching as well as identify the challenges they meet and needs they have. More specifically, the questions we aim to address in this paper are:

- Why do scholars choose particular resources over others for accessing the material they need?

- What are the challenges faced when accessing and interacting with digital resources?

- What effect can digital resources have on different stages of the research process?

Managing to answer these questions could foster significantly our understanding of art historical practice; this knowledge, in turn, could be applied to the creation of better digital resources and tools to support research and teaching in the field. Before presenting our results 
to illustrate our argument, though, it is necessary to provide some background details with regards to the information objects employed in art history as well as the practices that scholars follow in order to find the information they need. This will contribute to the building of a more detailed picture of art historians' profile as users of digital resources and libraries.

\section{Information Behavior in Art History}

\section{a) The discipline and its information objects}

Concerning the discipline of art history, scholarly behavior and researchers' needs is a subject that has been under examination for more than twenty years; though, even today, the needs of art historians seem insufficiently satisfied by digital technologies. According to recent studies [12, 37, pp. 19-22], art historians are still considered to be hesitant towards the adoption of technology, while many researchers are not convinced about the positive effect such technologies can have on their research.

However, this issue can be better understood if we consider several factors that characterize the field and make the employment of digital technologies for research purposes especially challenging. Firstly, the extensive list of subjects studied - many times interdisciplinary in nature - and methodological approaches employed by art historians today frequently require the use of a wide array of information objects (e.g. textual, visual and multimedia) in order to successfully answer a project's research questions. On the other hand, the different career stages of scholars, the various degrees of digital literacy as well as the difficulties often faced by researchers when using digital material - such as access problems, low image quality, copyright issues, cost [also see 14, p. 2, pp 9-11, 19, p. 6, p. 33, p. 40, 37, pp. 33-34] - can significantly impact the use of digital services and tools in research and teaching. Despite the challenges, though, art historians have started developing a greater reliance on digital resources [6, p. 30].

Thinking about the information objects used most frequently by scholars in this area, it is worth noting that, from the foundation of the discipline, art history has developed a close relationship with art objects; art objects tend to play a key role in art historians' research even when they are not the central topic under examination [also see 3, pp. 7-11, p. 7, p. 94, 8, pp. 
120-123]. Yet, although art objects play a principal role in art historical research, information objects in the field are not confined to artworks.

Instead, the information objects necessary for the art historical inquiry consist of an array of resources which complement, substantiate or even sometimes replace the works of art. These have conventional and digital form and they can be textual, visual and multimedia; mainly, they consist of the primary and secondary resources collected from libraries, archives and museums throughout the world. This wide variety of material has also been highlighted by several authors, such as Case [10, pp. 73-74] and Palmer, Teffeau and Pirmann [29, p. 18], who argued that historians' collections can be of the most diverse type, as they collect and study various resources, from archival and visual material to toys and objects related to the time and place of their project's subject; it is worth noting that Palmer, Teffeau and Pirmann [29], in particular, reached this conclusion after examining the collecting habits of researchers in several humanities and sciences discipline.

Of particular significance, though, for the field are the rare books and manuscripts and the visual material, which are considered necessary for the successful conduct of research in art history. More specifically, these information objects acquire additional value if the original art object is lost or difficult to access, as well as when the research subject itself places the art object in a secondary role; for example, when the main subject is the biography of an artist [also see 3, pp. 14-15, pp. 22-31, 8, pp. 122-123, 14, p. 3].

In the digital age, the places where art historians look mostly for the necessary information objects include various digital libraries and archives; databases with visual or other documentary material; digital journals and books; online thesauri, indices and dictionaries; discussion lists, various sites, relevant blogs and online communities [14, p. 3, 21 , p. 7, 32, pp. 735-750]. Harmsen [20], in 1996, argued that as the online material increases so will the level of importance that digital resources have for art historical research. Yet, although the use of digital resources has been significantly increased since Harmsen's observation and art historians consider them to be a standard part of their daily work routine, later studies [e.g. see 33, pp. 40-41, 37, pp. 33-34] showed that this does not necessarily indicate a greater degree of importance when compared, for example, with conventional resources; factors such as copyright or the quality of material available can affect their usefulness for scholars' work and, thus, their degree of importance. 
Hence, it is widely known that scholars in the field still rely greatly on the conventional material for their research and teaching practice. According to Rose [33, pp. 3738], digital resources were more likely to be treated as secondary material than to constitute the basic information object. However, she noted that this preference occurs more due to habit and a feeling of insecurity about digital technologies than indifference about the possibilities they can offer. A similar attitude applies towards the original work of art and its visual surrogates. Generally speaking, there is a strong desire to distinguish the original artwork from its reproductions [3, pp. 11-12, 30, p. 40]. Moreover, the emergence of digital visual surrogates has not managed to substitute the necessity to visit and examine the artwork in person [e.g. see 33, p. 37]. In particular, as lack of access, poor quality and copyright issues are problems art historians have to face frequently when dealing with digital images, the physical examination of the object seems unavoidable [e.g. see 14, pp. 9-11].

Nevertheless, despite the difficulties met, visual surrogates obtain further value and can be treated as primary information objects if the original artwork is lost or inaccessible [as in 3, pp. 14-15]. Also, they are valuable tools for publishing and teaching in art history, as well as for the analytical method of iconography where the comparison between visual representations of art objects is the main concern [e.g. see 3, pp. 19-20, 7, pp. 94-96, 8, p. 123]. Regarding digital images, more specifically, some of the recent studies in the field [6, $p$. 30,23 , pp. 53-54] have found an increase in their use compared to previous years, suggesting that scholars in the visual arts may have started trusting digital resources. In contrast to previous studies [15, p. 5, 33, p. 39], the results of Larkin's [23, pp. 53-54] research showed a new level of comfort with digital images in art historical scholarship. In particular, more than one third of the participants in her research agreeing to own a digital image collection were art historians. Yet, it should be noted that there are not many recent studies after 2010 documenting how the behavior of art historians has developed towards digital resources, along with the reasons behind it, an issue we aim to explore through this paper.

\section{b) Seeking for information}

According to Palmer, Teffeau and Pirmann [29, pp. 9-10] searching for research material can be a rather complicated activity for scholars. In art history, the beginning of the research process and, therefore, the seeking of the needed information, is to a great extent 
linked with the scholar's intuition and memory. These two qualities, which are associated with connoisseurship, apply especially to the case when research starts from the examination of the artwork. Brilliant [8, pp. 121-122], for example, noted that scholars in the field, after mainly relying on their visual memory to examine a work of art, attempt to search for related information objects.

In fact, artworks can often inspire the initiation of the art historical research process through enabling the discovery of the research subject and the generation of research questions. These questions, then, in combination with the experience of the researcher lead to the searching of the required material. At this point, it is worthwhile mentioning briefly the concept of inspiration and how it enables information seeking. A similar behavior with that encountered in art historians can actually be found in architects as studied by Makri and Warwick [25]. According to the authors [25, p. 1758], who examined the information seeking and use behavior of architects, one basic characteristic of the discipline, in general, but also of the behavior of scholars was creativity; for example, students in their research mentioned how the discovery of particular resources in their field inspired them with ideas for their current or future projects. Thus, it was argued [25, pp. 1767-1768] that the electronic resources and systems which are intended to support this type of behavior should be designed to enhance this fundamental quality of the research in the field.

One of the frameworks that Makri and Warwick [25] used for identifying and analyzing this type of behavior in architects was Shneiderman's Genex framework [35, pp. 119-124] which is considered appropriate for understanding creative information work. This framework includes four creative activities with regards to information - collect, relate, create and donate - and potential tasks associated with them [in 25, p. 1750]. Shneiderman, though, suggested that these activities are non-linear and creative work may entail going back to previous stages when required or include repetitive tasks [in 25, p. 1750].

However, the relevance of this framework for this paper lies in the fact that art history is a highly creative discipline, which as we said before uses art works not only as information objects but also as a source of inspiration. Therefore, from the perspective of Shneiderman's framework, it can be argued that the gaining of information from artworks- information that work as inspiration drive for information seeking at the initial stages of art historical research- can constitute a task that belongs to the collect activity. An additional remark here may be that this particular role of artworks as inspiration for further information seeking 
should be taken into account when designing digital tools and services for supporting art historical scholarship.

Continuing with the examination of the first stages of the research process in art history, Bailey and Graham [2] suggested that the types of information objects required each time for conducting a project in the field, as well as the way the research will continue, are determined by the research subject. At this early stage of research, Bakewell, Beeman and Reese [3, p. 111] argued that every possible resource may prove useful. However, when art historians start looking for information to support their research questions, they have to deal with a variety of difficulties. As mentioned earlier, the diverse information objects that scholars need are usually scattered all over the world; thus, travel becomes an inevitable part of the research process in the discipline. Yet, although digitization of information and the provision of online access to material have not yet managed to replace this need to travel, they have considerably reduced the time to seek and discover the necessary resources [also in 33, p. 40].

Regarding the practices employed for finding information, chaining and browsing are those preferred in the discipline. In fact, this is one of the reasons why Beaudoin [5, pp. 3435] argued that art historians' information seeking behavior matches Mann's [26] 'Subject or Discipline Model' and 'Library Science Model' of information seeking as well as Bates' [4] 'berrypicking' model. According to these models, the great reliance on libraries for browsing material and the use of bibliographies, citations, indices and abstracts for tracking resources are among the characteristics fitting art historians' information seeking behavior.

To begin with, chaining is a significant information seeking activity in art historical research and it is usually carried out through, principally, textual resources such as books, articles, bibliographic catalogues, references and footnotes [also see 8, p. 126]. In addition, art historians prefer to use chaining not only for finding relevant research material, but also for staying up to date with the latest news in their field [2, p. 752]. In the digital environment, various databases, such as indices and online catalogues, have been designed to meet these specific needs [13, pp. 225-226, 32, pp. 737-741].

Regarding browsing, it tends to be a popular activity among Arts \& Humanities scholars and has been traditionally conducted in libraries around the world. Brockman et al. $[9$, p. 13] argued that this is because printed versions of books and journals are to a great 
degree suitable for browsing and easy to use. Yet, it is well known that art historians are especially interested in browsing databases containing digital surrogates of artworks; in fact, they constitute one of the primary places of interest for searching visual material.

Also, this activity, as Palmer, Teffeau and Pirmann observed, differs from the other information seeking activities; 'browsing tends to be open ended with the searcher looking through a body of assembled or accessible information' [29, p. 13]. Furthermore, as browsing

[...] tends to be broad and flexible, scholars encounter materials that would not be found through searching or chaining, and the new information may stimulate unexpected and fortuitous intellectual connections [29, p. 14].

In that way, browsing enables serendipitous discovery [see also 13, pp. 217-218, 29, p. 14], a valuable aspect of information seeking to bear in mind when designing digital tools and services for enabling information searches.

Finally, networking and informal communication with colleagues are practices that are commonly employed across Arts \& Humanities to discover information. Regarding art history, Stam [36, pp. 28-29] referred to the communication between colleagues in the field as the 'invisible college', constituting an important part of the information seeking behavior of art historians. Being in the digital age, these activities are supported by a range of tools and services. E-mail, discussion lists, forums, blogs, online conferencing services and other online communities are some of the digital tools and services that enhance these activities and, thus, scholars' information seeking [e.g. see 7, pp. 99-100, 19, pp. 5-6, 21, p. 4].

\section{Methodology}

This study employed an ethnographic approach to the study of scholarly practices by conducting semi-structured, in-depth interviews with twenty art historians as well as observation of their physical and digital personal information collections in order to identify the particular needs they have when they build them. We argue that personal collections, being at the core of art historians' workspace [also see 24, pp. 23-25], are an important starting point for understanding behavior and practices that are difficult to study otherwise, due to the private nature and the various personal criteria applied. 
For the purposes of this project, single face-to-face and Skype interviews with twenty art historians were conducted. These took place from June 2013 to October 2013 and, in terms of format, they were semi-structured, based on an interview guide, while each of them lasted approximately one hour. The interviews were recorded with the written consent of the participants and then transcribed using the Express Scribe software. Moreover, the interviewing phase included, when possible and with the interviewees' consent, observation of the interviewees' personal physical and/or digital collections. Again, when possible, gaining photographs of scholars' collections constituted a part of the observation process.

Regarding the profile of the research participants at the time of the interviews, sixteen were based at UK institutions, while two scholars were based in Europe and another two outside of Europe. Eleven of the participants were female and nine of them male, whereas age was not a prime concern for this study. Moreover, it is worth stating that their technical skills varied from advanced to basic. Also, the interviewees were at different career stages and, thus, they ranged from established academics to PhD students, early career researchers as well as independent scholars.

We were particularly interested in creating a pool of interviewees consisting of two groups; one where scholars worked on commonly studied areas (e.g. various areas of European art, like Renaissance art) or employed traditional art historical methods (e.g. stylistic analysis, historical investigation) and another where the topics examined (e.g. nonWestern art, digital art) or the methods employed (e.g. quantitative, digital) were considered less traditional. Yet, it should be mentioned that this categorization was based on the premise that the practices of scholars in the first group (twelve scholars in this study) had been frequently examined by previous studies in the field while the behavior and needs of those in the latter (eight scholars in this study) had been less studied before [also see 33, p. 37]. Identifying any similarities and differences between these two different groups of scholars could provide a better insight into the needs that art historians in different areas of the field have in terms of resources, tools and services.

Thus, the eras the interviewees explored through their projects ranged from the 14th century to today, including Byzantine art, medieval art, Renaissance, contemporary and modern art, 3D documentation of material cultural heritage, and art history education. As a result, there was large diversity in terms of the objects of study in scholars' work; these ranged from actual objects (e.g. paintings, sculpture, manuscripts) and monuments (e.g. 
churches) to historical and other issues in relation to art and its artists, such as arts education and the creation of guidelines and standards.

When the transcription phase was completed, and before the analysis stage, the transcripts were sent to the participants who confirmed the accuracy of their content. The analysis of the interviews was conducted using the NVivo software for qualitative research and the transcripts were coded according to a grounded theory approach. We started with axial coding, through identifying themes, categories and sub-categories in the data as well as specifying their properties. Then, selective coding was considered necessary for creating links between the different themes and categories and refining the codes until the issues raised during their analysis were of satisfying quality and depth and could be used to answer the study's research questions. The analysis procedure was complemented by the memos (reflective notes) that were kept during the coding process and the photographs and the notes taken during or after the observation which worked as a method for achieving triangulation, and thus, more accurate results.

To conclude, it may be useful to note that a theoretical framework consisting of empirically tested information behavior models was used to analyze the interview and observation data. The models that enabled us to develop a sound understanding of art historians' information behavior included Ellis's [16] features of information seeking, along with the additional features presented by Meho and Tibbo [27]. Ellis's and Meho and Tibbo's models, in particular, were useful for identifying the distinctive behavior of art historians in terms of the way they look for information during the initial stages of their research. Furthermore, Kuhlthau's Information Search Model (ISP) model [22], which is concerned with the cognitive aspects of information seeking, was valuable for understanding the reasons behind certain decisions that scholars made when interacting with digital resources and facilitated our exploration of the scholarly practices that follow information discovery. Shneiderman's framework, on the other hand, enabled the interpretation of our data concerned with the creative interactions of scholars with information. Finally, given the fact that we used scholars' personal collections of information to examine how art historians collect, use and manage information for research and teaching, Palmer, Teffeau and Pirmann's [29, pp. 16-19] scholarly activities and primitives were fundamental for examining the practices (gathering and organizing) related to the building of personal collections. 


\section{Results}

\section{a) Accessing digital material}

Generally speaking, many of the interviewees participating in this project tended to start their research online [as also in 1, p. 282] or from their personal collections and the material they had usually at their home office; then, if considered necessary (based on the factors and criteria that will be discussed later), would choose to visit specific resources in person. Regarding the information seeking practices followed by art historians in this study, it can be argued that chaining and browsing were the two most commonly employed. Also, colleagues constituted an important part of the initial stages of research, from the understanding of the topic under study to the finding of the necessary information, especially in the cases where scholars were faced with challenges during its discovery and access.

Thinking about the types and formats of the information objects utilized by art historians in this study, they were to a great extent similar to those from previous studies [e.g. see 32, pp. 734-735, 33, p. 37]. Yet, since some of our interviewees were conducting nontraditional research, non-common types of information objects were also employed, such as 3D models and visualizations, mailing lists, or internet artworks which often raised different issues and requirements when compared to those more traditionally employed (as it will be shown later). Although the diversity of resources used for research and teaching in the field of art history was something that, to a large extent, was expected, there are several issues with regards to this finding that are worthwhile discussing further.

Firstly, it should be highlighted that the original artworks and other objects of study in their original form - these could include monuments, manuscripts, Japanese hand-scrolls - the primary resources, such as archival material, and visual surrogates (physical or digital) were the information objects with the greatest significance for these scholars, confirming in that way several earlier studies whose findings were presented earlier [e.g. see 3, 7, 14, 5]. For instance, as Participant 04 (categorized as conducting traditional research) clearly explained, an art object or an image could provide the inspiration for kick-starting the actual research on a project.

Personally, I tend to start with objects or images. So, an interest will often be sprung by looking at an image - often online just because it's 
easy to access - either in an image library or normally a museum website.

[Participant 04]

This quote brings to mind Makri and Warwick's [25, p. 1758] finding about the inspirational effect that information had on the work of the postgraduate architecture students in their study. By using Shneiderman's Genex framework [35, pp. 119-124] to interpret the data collected in our study, we were able to suggest that art history, as in the case of architecture, is a highly creative discipline; in fact, as scholars reported, information found online could trigger new ideas for current and future projects.

Continuing, many of the art historians in this study tended to be aware of, at least, the main places they had to visit (digital or physical) to find information related to their work. This behavior, which was mostly based on previous experience and habit, was complemented by other information seeking practices (e.g. consulting colleagues) in order to eliminate the chances of missing other useful resources they were not aware of. Yet, knowing where to start looking for information that is relevant to one's topic did not necessarily mean that the process to access it was easy. More specifically, travelling was a choice many had to make for consulting not only primary resources, but secondary as well. Participant 08 (categorized as conducting non-traditional research), who was researching 19th century Japanese painting, had, amongst other places, to visit Japan, since part of the information needed was not accessible in any other way.

And so, I've got all of that in Japan because it's very hard to get those books here. [...] I'm reading as well manuscripts, handwritten books, as a sort of social context. [Participant 08]

This issue generates questions regarding the extent to which information resources available online - even when including secondary material - meet the needs of scholars in the various sub-disciplinary areas of art history, like non-Western art. Actually, the art period a project was looking at, the geographical focus of its subject (e.g. non-Western art) or the fact that the topic under investigation may have not been researched before were often connected to issues of availability of resources, conveniently accessible to scholars.

Another interesting aspect of the findings in terms of the online places visited in the context of research was the fact that social media and social networks (specifically Facebook, Twitter and YouTube) proved places where scholars researching particular topics could find information that was hard to find anywhere else. This could include documentary videos, 
interviews and other oral history types of information about people, objects and practices which could be discovered either through searching or by asking relevant community groups. Yet, although there are several studies focusing on humanists' behavior [e.g. 31, 34], there is limited understanding of how social media, social networks or blogging are used by art historians in the context of the research process, e.g. during information-seeking, which is a topic worth examining further in future research.

Concerning the digital collections used by scholars in the field of art history, it may be worth noting that only one of the interviewees referred to any of the large, collaborative, European online initiatives which enable the discovery of primary and secondary material. In this one case, Participant 09 (digital art historian) referred to Europeana Regia (containing manuscripts); however, the brief commentary below suggested that the design of the resource might not fit the needs some of the art historians interested in manuscripts might have.

The ways you can search are very limited and it's very rare actually to find a project that has been created with the end user in mind. [Participant 09]

Despite the challenges, digital resources and services were useful when scholars did not have a concrete idea of the kind of information they were looking for or where exactly to find it. Participant 17 (digital art historian) shared the reasons why they find particular resources helpful under such circumstances.

There are bodies of work that I remember even if I don't remember about exactly how I'm going to find them or where they are. Resources like Rhizome are really useful because for a long time they archived a lot of Internet artworks. So that's a good cause of call which is as similar as it gets to going to an art gallery because I can look of an artwork in that archive but I can also more often than not find discussion that surrounds that artwork. [Participant 17]

Thinking further about the reasons why scholars may prefer to start their research on a project online, apart from the lack of geographical limitations, it seems that the possibility of a serendipitous discovery that such a choice may entail is considered an important factor. For example, Participant 04, while talking about image search, underlined the fact that using Google Images may lead to unexpected findings. 
Normally, it's museum websites. [...] But I suppose Google Images throws up stuff that you might not have known otherwise. [Participant 04]

Also, Participant 03's (categorized as conducting traditional research) account of the way they look for material on the Web may suggest that serendipity can influence the material that is going to be collected in the context of a research project.

I mean, there are a lot of these very early texts, these are Victorian texts, all do these seem to be often on the Web somewhere, but I don't intend to go looking for them now. If they come up, I'll go for them [unclear]. But I don't tend to go looking for them. [Participant 03]

Concerning the issue of serendipity, more specifically, several studies have looked into its role in scholarly practice and examined whether it can be supported by information systems. For instance, Foster and Ford [17] studied serendipity in the context of the information seeking behavior of interdisciplinary scholars (including Arts \& Humanities) and suggested that further examination is needed in order to understand that phenomenon which, as they argued, is '[...] a difficult concept to research since it is by definition not particularly susceptible to systematic control and prediction' [17, p. 337].

Thinking about the findings presented here, several of the art historians provided examples illustrating the fact that serendipity can be experienced not only through the use of conventional formats, but through the use of digital services as well. More specifically, it can be argued that the issue of serendipity was more likely to occur during the first stage of information seeking when scholars attempted to investigate a topic. On the other hand, encountering interesting information was more difficult during the later stages of research when scholars were looking for more specific and focused information to support and enhance their argument. Also, the fact that some areas of research were found to benefit from a larger pool of online resources cannot be overlooked when considering the possibilities of discovering information serendipitously. Yet, given the limited information available with regards to this aspect of information behavior of art historians, further exploration will certainly prove valuable for increasing the positive impact that digital resources can have on research and teaching in the field. 


\section{Using digital resources}

\section{a) Criteria for choosing resources}

In this section, the aim is to present the factors which influenced scholars' behavior when choosing resources to use as well as the actions that followed the discovery of information, highlighting the impact that digital resources and libraries can have on the research process. To begin with, convenience was one of the issues that influenced researchers' decisions with regards to which places to visit and it was often associated with easy access to digital and physical resources provided by the places where the scholars worked or studied.

On the other hand, and particularly when the place they were based did not offer a good variety of resources, scholars tended to visit other places which were either geographically close to them or were considered worth visiting for particular reasons. In the latter case, the most common reason was the degree to which the material that could be found at a specific library, museum or archive (physically or digitally) was relevant to the topic researched or taught; the accessibility of this material, especially in relevance to cost (due to travel or copyright issues); breadth and quality of material; and reliability of source.

Considering the visual resources, in particular, although the factors described previously applied in this case as well, accessibility in relation to cost incurred by copyright reasons and quality of material available were often two of the most important criteria scholars took under consideration when looking for related material. Thinking about reliability as a factor for choosing the resources to be consulted and the material to be used and quoted in the context of research or teaching in the field, art historians participating in this study explained their criteria for trusting information. Based on our findings, trusting the author or the institution providing the information were the two paramount criteria for scholars when deciding upon the resources to be consulted and used. Other criteria included trusting the publisher or particular resources frequently used in academia (e.g. JSTOR). Additionally, previous experience and intuition often came up as the researcher's tools when evaluating the trustworthiness of a resource.

However, there were some cases where the above criteria were not enough in order to judge the reliability and quality of a resource. For instance, according to Participant 07 below 
(categorized as conducting traditional research), language can pose its own challenges when scholars attempt to make related judgements.

I think I had a specific challenge like anyone who is working across languages and working across different areas of scholarship. Spanish scholarship is very different. The approach to scholarship is very different than in the English language and I think I struggled with that at first because it's not my first language and it's hard to tell from the quality of writing; that's often a good gauge in a sense that someone is writing comfortably about something and you can get a sense of it. [...] But I didn't have that advantage with Spanish. [Participant 07]

In the case of this participant, it is worthwhile underlining the connection between the interdisciplinary nature of research and the challenges posed by it, such as those described in terms of language, which inevitably increases the degree of complexity when looking for information and, thus, may imply particular information needs. As Palmer and Neumann [28, p. 107] argued, translation can complicate information seeking and gathering as well as other scholarly practices (e.g. reading) and, therefore, there is greater necessity to understand the information practices and needs of scholars in the Arts \& Humanities conducting interdisciplinary research. Furthermore, research projects examining non-traditional topics such as internet art, which may require the consultation of non-traditionally used resources (e.g. mailing and discussion lists) may lead to alternative methods for confirming the reliability of such information; in the case of Participant 17, a method for checking the trustworthiness of the discovered material was to contact the responsible people (e.g. artists).

In terms of trusting resources, I suppose because I studied Internet Art, a lot of material that surrounds Internet Art, a lot of the online mailing list based discussion was not especially deliberately falsified; there were lots of text based stands where artists were using discussing spaces to create alternative histories. [...] So, it's harder for me to assume that something is valid just because it exists, like I can't say 'Oh, it's in a book, therefore the publisher and various other people have agreed to this'. So I probably then got a lot of the time to go and talk to the people who were involved. [Participant 17]

Finally, aspects of the design of a resource, such the way digitization has been conducted or its interface, and the experience it offered, as a result, to the user was a factor influencing scholars' information behavior. Participant 09, based on their experience with online collections containing digitized material, gives an example of potential problems that 
can be encountered when using a digital resource, while Participant 03 explains why they avoid using particular resources.

I mean, I have a manuscript in Rome. It's held in another library, not in the Vatican, and they have digitized their collection, but for some reason that I'm still trying to understand they have digitized only the decorated part of the page. So, basically I get a decorated initial and I cannot read the text. [...] There are choices that have been made online that to me are completely absurd. [Participant 09]

Therefore, such issues were not only the reasons some scholars preferred to consult an art object in person, but they could also constitute factors influencing their decisions as to which resources to use more generally.

\section{b) Gathering Information}

Thinking about art historians' behavior after the discovery of information, Palmer, Teffeau and Pirmann [29, p. 16] highlighted our limited knowledge around practices such as the gathering and organizing of information, along with any patterns in scholarly behavior. Gathering particularly can be challenging to study; the reasons why scholars decide to gather specific information the moment they discover it as well as in what fashion they collect it are details that are difficult to capture. However, the analysis of the interviews brought up several issues regarding the actions of scholars after information discovery.

Generally speaking, art historians in this study collected any material they considered of importance for the purposes of their projects at that time or in the future; this finding is in accordance with earlier studies about Arts \& Humanities scholars' gathering habits [e.g. see 29, pp. 16-17]. Yet, the design of this study and the employment of relevant information behavior models enabled the identification of a pattern in their gathering behavior not previously recorded. Starting with Kuhlthau's Information Search Model (ISP) [22, pp. 366368], and comparing the behavior of the art historians' participating in this study to the different feelings, thoughts, actions and tasks associated with each stage of the model, ${ }^{1}$ it was decided that the exploration and collection stages would constitute our main focus. This is because these stages and their properties were most relevant to explain the patterns identified

1 The stages included in the ISP model are: initiation, selection, exploration, formulation, collection, presentation. Each stage has associated feelings, thoughts, actions and tasks and can be found in Kuhlthau [22, p. 367]. 
in our data and, more specifically, the fact that our participants' gathering behavior tended to consist of at least two main phases (see Table 1 below). Although in Kuhlthau's model the gathering of information takes place only when the user has developed a certain confidence in their topic and, thus, it is naturally more focused, art historians in this study began gathering material much earlier, at the time resembling Kuhlthau's exploration stage (when uncertainty is more common).

Indeed, apart from being conducted in the context of exploring a new topic at the beginning of research, this first phase of gathering was often a result of the feelings associated with the obstacles (e.g. frustration due to limited access) encountered during the information seeking process (corresponding to Kuhlthau's exploration stage), making the need to gather as much as possible (digitally and physically) more intense. Then, a more focused gathering phase was identified which often took place at a more progressed stage (after reading and during writing) of the research (especially in the cases where projects lasted for a long time) and it bore similarities to Kuhlthau's collection stage. Yet, as Kuhlthau argued, it is possible for users to gather information during various stages of the research process based on their particular behavior and needs, while entering the writing stage as well as conducting an initial organization of the collected material may enable them to develop this more focused approach which leads to a second phase of gathering [22, pp. 368-369].

Table 1. The gathering phases and their characteristics

\begin{tabular}{lll}
\hline Characteristics & $\begin{array}{l}\text { Exploratory Gathering (1st } \\
\text { phase) }\end{array}$ & $\begin{array}{l}\text { Focused Gathering (2nd } \\
\text { phase) }\end{array}$ \\
\hline Action & $\begin{array}{l}\text { Seeking \& Gathering relevant } \\
\text { information }\end{array}$ & $\begin{array}{l}\text { Seeking \& Gathering focused } \\
\text { information }\end{array}$ \\
\hline Task & Investigate/ Explore the topic & $\begin{array}{l}\text { Build/ Enhance the research } \\
\text { argument (often during } \\
\text { writing) }\end{array}$ \\
\hline Stage of research & Early & $\begin{array}{l}\text { Progressed } \\
\text { Type }\end{array}$ \\
\hline Intensity & Non-selective & Selective/ Discriminate \\
\hline Information amount & Large & Low \\
\hline Feelings & Uncertainty/ Frustration & Small \\
\hline $\begin{array}{l}\text { Effect on personal } \\
\text { collections }\end{array}$ & $\begin{array}{l}\text { Creation \& Initial organisation } \\
\text { of information }\end{array}$ & $\begin{array}{l}\text { Further information } \\
\text { organisation/ Re-structuring }\end{array}$ \\
\hline
\end{tabular}

Therefore, after using Kuhlthau's ISP model to closely examine the behavior of art historians that followed the discovery of information and identifying the impact that the challenges associated with digital resources can have on this process, a variation of the model 
was suggested. This should include an additional gathering task at the exploration stage called Exploratory Gathering which will follow the Exploratory Information Seeking conducted beforehand. Moreover, the second gathering task (with the same characteristics as the one described in the model) can be named Focused Gathering and will come after the Focused Information Seeking.

This finding was also examined from the perspective of other information seeking studies which include aspects of information collection in their models (e.g. information gathering, information managing), such as Shneiderman's framework (2000) or Meho and Tibbo's [27] extended version of Ellis's information seeking model. More specifically, based on the assumption that there are two - at least - distinct stages of information seeking (of different nature and with different purpose) preceding the different gathering phases, we can then talk about repetitive tasks or a need to go back to a previous stage and, hence, refer to Shneiderman's framework [35, pp. 119-124]. Shneiderman suggested that non-linearity or repetitive tasks can be part of the information seeking behavior in creative areas while users can have different needs during these tasks. Having argued that art historical practice could be characterized as creative, especially in terms of its interaction with information, these observations suggest that art historians have different information needs during the different phases of their information seeking and gathering activities. This finding constitutes an addition to our current knowledge about the information seeking and gathering behavior of art historians and should be taken into consideration when designing digital resources and tools to support scholarship in the field.

Finally, if we consider art historians' behavior during the exploratory stage in more detail (as noted previously), gathering information indiscriminately early in the research process can pose information management challenges for scholars later in their research and have an impact on other scholarly activities (e.g. reading, writing). As discovered in this research, scholars often had to take action with regards to the management of the collected material, and sometimes even discard information, in order to be able to use it effectively. This observation, then, brings to mind Meho and Tibbo's [27, p. 584] argument about information managing; even though it is not considered an actual information seeking task, information managing is an essential activity in the cases where personal collections play an important role in the research process (as in the case of the art historians in our study), since it can affect other scholarly practices and tasks conducted in the context of research, such as 
information retrieval (in personal collections). Thus, understanding that the problems that art historians face with regards to the use of digital resources can have an impact on different stages of the scholarly workflow is a necessary step towards meeting their needs and improving the research process.

\section{Discussion}

To begin with, it is necessary to re-state that previous studies' findings on the limited access to useful resources, such as good quality visual information, that their participants were experiencing [e.g. 18, 33] were again validated in this research. Despite the progress that digitization projects have made over the years and the increase in the availability of online material, it became evident that scholars lack digital access, particularly to primary resources and good quality, open access visual material.

More specifically, interviewees in some areas of study, such as Asian and Japanese art, faced greater difficulty in finding these types of material online; unsurprisingly, the availability of digital resources on the Web tended to be greater in areas dealing with Western art of particular popular eras (e.g. Renaissance art, $18^{\text {th }}$ and $19^{\text {th }}$ century art). It should be highlighted that the call to conduct such an examination was first mentioned in Rose [33, p. 41] and has not been explored by other studies looking at the information practices of art historians since then. Also, it should be noted that research focusing on modern and contemporary art would be significantly enhanced by resources which could bring material useful to researchers (e.g. material already available on the Web) together in one place; given that these areas are constantly being shaped by new research, scholars need to be continually updated with regards to new material in their areas of interest. Moreover, since research on the areas described earlier (Non-western art, modern and contemporary art) has been found to be on the rise [see, for example, 24, p. 17], issues of accessibility to resources that meet these art historians' needs become more pressing.

Given the issues stressed so far, it was inevitable that easy access to material (including costs of copyright) would be one of the primary criteria for the research participants when choosing resources to access online and use. The institutions where most of them were based or other easily accessible and frequently visited places (e.g. libraries, 
museums, archives) were some of the key access providers to material relevant to scholars' projects which had also earned their trust. Previous experience with a resource (or similar resources) and the researcher's intuition were also influential factors when deciding which resources to visit virtually or physically.

Also, it should be highlighted that the problems often faced when interacting with digital resources during these first stages of research were found to affect the gathering behavior of scholars in the field. Thus, art historians often felt the need to collect as much material as possible at the beginning of a project; yet, gathering information indiscriminately early in the research process (from the exploratory stage) could pose challenges for scholars later in their research (e.g. information management) and have an impact on other scholarly activities, such as reading, writing. The variation of Kuhlthau's [22] model presented here aimed to highlight the different needs that art historians can have during different stages of the research process and suggests that digital resources should be built accordingly to meet their requirements.

Thinking about other criteria for choosing resources to use, it is worth further highlighting the issue of language which constituted a consideration for scholars who often researched on highly interdisciplinary topics across the Arts \& Humanities. Actually, whenever the gathering of this type of material was regarded as essential for the purposes of a project, the challenges posed could affect other information and scholarly practices; for example, the information seeking process could be postponed until the attainment of the required language skills. Given that art history is a highly interdisciplinary field in terms of topics studied and methods employed, it became clear in this study that barriers posed by language could influence the research process, an additional issue to take into account when creating resources targeted to art historians in the digital age.

On the other hand, there were cases where participants reported gaining inspiration to start researching on a topic through finding images in places such as digital libraries. In fact, this possibility of a serendipitous discovery was one of the reasons that many of these art historians preferred to start their research online. Thus, it is worth highlighting the positive effect that access to good quality digital resources (e.g. image libraries) can have on initiating the research process, through enabling the identification of a topic or triggering further information seeking activity. Managing to facilitate serendipity through the provision of appropriate tools and services will significantly enhance scholarship in the field. 
Moreover, the use of social media and social networks as resources for finding information related to a research project was a discovery not encountered in previous studies looking at the information practices of scholars in the field. Although art historians were generally hesitant towards the use of these types of resources, they were keener to employ them when there was a general lack of resources in their area of study or when they constituted the only way to find out about specific information. However, despite the frequent study of the use of these services - especially for scholarly communication purposes - in other areas of the Arts \& Humanities [e.g. see 31, 34], there has been little research examining the different uses and the impact of these types of digital media and services on art historical scholarship.

Finally, it is worth closing by mentioning again some of the participants' comments about the apparent interpretative choices that had been made to the content of specific digital resources or to the searching problems encountered due to the way that the material was classified and catalogued. In fact, as became evident through the interviews, such editorial choices could reduce the usefulness of the digitized content for scholars, who would then look for another resource online or, if possible, visit the resource physically. Therefore, incorporating scholars' (as the potential users) views early on in the digitization process (e.g. through understanding their needs), providing essential information about some of the core choices that have been made during the building of a digital resource as well as gaining user feedback about aspects of the interface design, will not only increase its usefulness for scholars and earn their trust but can also prove beneficial for the longevity of this resource.

\section{Conclusion}

To conclude, the results of this study suggested that scholars in the field become increasingly aware of the effect that digital technologies can have on their work, from the seeking of the information to the analysis of their data. Additionally, it became apparent that, although they tend to employ a wide range of resources in their daily work routine, the different behavior and needs of the various sub-disciplinary groups remain understudied. However, by using scholars' personal collections of information as a starting point for exploring how they access and use digital resources in research and teaching, we managed to uncover aspects of disciplinary scholarly practice rarely discussed before. 
More specifically, the finding concerning the impact that the design of a digital resource (beyond its searching capabilities) can have on whether scholars in the field would use a specific resource was an issue that has not been raised before. Also, social media have started to emerge as places where art historians' actively look for information, especially when they face problems accessing other resources; given that our awareness around art historians' engagement with social media is limited, this finding furthers our knowledge of this aspect of scholarly research. Moreover, at least two different stages of information seeking were found to occur in the course of a project where scholars had different information needs during each of them, a new discovery which has direct implications for digital resource design. Lastly, by employing of Kuhlthau's [22] ISP model as the basis for building this argument, we achieved to extend and vary it.

Overall, the findings presented in this paper have enhanced our understanding of some of the core information practices associated with the discovery of information and the steps that follow this; in that way, they contribute to our knowledge about the requirements that art historians have at the early stages of research and beyond as well as the criteria upon which their decisions are made when interacting with digital resources and libraries, which have been underexplored. Finally, this paper has hopefully brought to the fore issues for consideration for information professionals and other scholars interested in understanding and supporting art historical scholarship with appropriate tools and services in the digital age. 


\section{References}

1. Antonijević, S, Stern Cahoy, E (2014). Personal Library Curation: An Ethnographic Study of Scholars' Information Practices. portal: Libraries and the Academy, 14(2), pp. 287306.

2. Bailey, C, Graham, ME (2000). The Corpus and the Art Historian. Thirtieth International Congress of the History of Art. Art History for the Millenium: Time, London, UK, 3-8 September 2000. International Committee for the History of Art (CIHA). https://unites.uqam.ca/AHWA/Meetings/2000.CIHA/Bailey.html.

3. Bakewell, E, Beeman, WO, Reese, CM (1988). Object, Image, Inquiry. The art historian at work. J. Paul Getty Trust, United States of America.

4. Bates, MJ (1989). The design of browsing and berrypicking techniques for the online search interface. Online Review, 13(5), pp. 407-424.

5. Beaudoin, J (2005). Image and Text: A Review of the Literature Concerning the Information Needs and Research Behaviors of Art Historians. Art Documentation: Journal of the Art Libraries Society of North America, 24(2), pp. 34-37.

6. Beaudoin, JE, Brady, JE (2011). Finding Visual Information: A Study of Image Resources Used by Archaeologists, Architects, Art Historians, and Artists. Art Documentation: Journal of the Art Libraries Society of North America, 30(2), 24-36.

7. Beeman, A (1995). Stalking the Art Historian. In: Shields, M.A. (Ed.) Work and technology in higher education: the Social Construction of Academic Computing. Lawrence E. Earlbaum, Montclair, N.J., pp. 89-102.

8. Brilliant, R (1988). How an Art Historian Connects Art Objects and Information. In: Stam, D.C. \& Giral, A. (Eds.) Linking Art Objects and Art Information. Library Trends, 37(2), pp. 120-129.

9. Brockman, WS, Neumann, L, Palmer, CL, Tidline, TJ (2001). Scholarly Work in the Humanities and the Evolving Information Environment. Digital Library Federation and Council on Library and Information Resources, Washington, D.C.

10. Case, DO (1991). The Collection and Use of Information by Some American Historians: A Study of Motives and Methods. The Library Quarterly, 61(1), pp. 61-82.

11. Challener, J (1999). Information-Seeking Behavior of Professors in Art History and Studio Art. Master's Research Paper, Kent State University. http://www.eric.ed.gov/PDFS/ED435405.pdf.

12. Cuno, J (2012). How Art History is failing at the Internet. The Daily Dot. http://www.dailydot.com/opinion/art-history-failing-internet/.

13. Dallas, C (1998). Humanistic Research, Information Resources and Electronic Communication.

http://pandemos.panteion.gr:8080/fedora/objects/iid:773/datastreams/PDF1/content.

14. Durran, J (1997). Art History, Scholarship and Image Libraries: Realizing the Potential of the Digital Age. http://www.scribd.com/doc/3799275/Art-History-Scholarship-andImage-Libraries-Realising-the-Potential-of-the-Digital-Age.

15. Elam, B. (2007) Readiness or avoidance: e-resources and the art historian. Collection Building, 26(1), pp. 4-6. 
16. Ellis, D (1993). Modeling the information-seeking patterns of academic researchers: A grounded theory approach. The Library Quarterly, 63(4), pp. 469-486.

17. Foster, A, Ford, N (2003). Serendipity and Information Seeking: an empirical study. Journal of Documentation, 59(3), pp. 321-340.

18. Greenhalgh, M (2004). Art History. In: Schreibman, Siemens \& Unsworth (Eds.), A Companion to Digital Humanities. Oxford: Blackwell. http://bit.ly/1XdB1Jr.

19. Grindley, N (2006). What's in the Art-Historian's Toolkit? A Methods Network Working Paper. AHRC ICT Methods Network. http://www.methodsnetwork.ac.uk/resources/wkp01.html.

20. Harmsen, L (1996). The Internet as a Research Medium for Art Historians. The Art History Research Centre. http://harmsen.net/ahrc/essay.htm.

21. Kamposiori, C, Benardou, A (2011). Collaboration in Art Historical Research: Looking at primitives. Kunstgeschichte, Open Peer Reviewed Journal. http://www.kunstgeschichteejournal.net/157/.

22. Kuhlthau, CC (1991). Inside the search process: information seeking from the user's perspective. Journal of the American Society for Information Science, 42(5), pp. 361-371.

23. Larkin, C (2010). Looking to the Future While Learning from the Past: Information Seeking in the Visual Arts. Art Documentation: Journal of the Art Libraries Society of North America, 29(1), pp. 49-60.

24. Long, M, Schonfeld, RC (2014). Supporting the Changing Research Practices of Art Historians. ITHAKA S+R, 30 April 2014. http://www.sr.ithaka.org/researchpublications/supporting-changing-research-practices-art-historians.

25. Makri, S, Warwick, C (2010). Information for inspiration: Understanding architects' information seeking and use behaviors to inform design. Journal of the American Society for Information Science and Technology, 61(9), pp. 1745-1770.

26. Mann, T (1993). Library Research Models. A Guide to Classification, Cataloging and Computers. Oxford University Press, pp. 9-56.

27. Meho, LI, Tibbo, HR (2003). Modeling the Information-Seeking Behavior of Social Scientists: Ellis's Study Revisited. Journal of the American Society for Information Science and Technology, 54(6), pp. 580-587.

28. Palmer, CL, Neumann, LJ (2002). The information work of interdisciplinary humanities scholars: exploration and translation. The Library Quarterly, 72(1), pp. 85-117.

29. Palmer, CL, Teffeau, LC, Pirmann, CM (2009). Scholarly Information Practices in the Online Environment. Themes from the Literature and Implications for Library Service Development. Graduate School of Library \& Information Science (GSLIS), Center for Informatics Research in Science \& Scholarship (CIRSS), University of Illinois at UrbanaChampaign. OCLC Research, Dublin, Ohio. https:/www.loc.gov/item/lcwa00095544/.

30. Promey, SM, Stewart, M (1997). Digital Art History: A New Field for Collaboration. American Art, 11(2), pp. 36-41.

31. Quan-Haase, A, Martin, K, McCay-Peet, L (2015). Networks of digital humanities scholars: The informational and social uses and gratifications of Twitter. Big Data \& Society, 2(1), pp. 1-12.

32. Reed, M (1992). Navigator, Mapmaker, Stargazer: Charting the New Electronic Sources in Art History. Library Trends, 40(4), pp. 733-755. 
33. Rose, T (2002). Technology's Impact on the Information-Seeking Behavior of Art Historians. Art Documentation, 21(2), pp. 35-42.

34. Ross, C, Terras, M, Warwick, C, Welsh, A (2011). Enabled backchannel: conference Twitter use by digital humanists. Journal of Documentation, 67(2), pp. 214-237.

35. Shneiderman, B (2000). Creating Creativity: User Interfaces for Supporting Innovation. ACM Transactions on Computer-Human Interaction - Special issue on human-computer interaction in the new millennium, Part 1, 7(1), pp. 114-138.

36. Stam, DC (1984). The Information-Seeking Practices of Art Historians in Museums and Colleges in the United States, 1982-83. PhD Thesis. Columbia University, US.

37. Zorich, DM (2012). Transitioning to a Digital World: Art History, Its Research Centers, and Digital Scholarship. Report to the Samuel H. Kress Foundation and the Roy Rosenzweig Center for History and New Media, George Mason University. http://www.kressfoundation.org/news/Article.aspx?id=35338. 